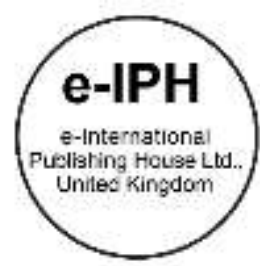

\title{
Acceptable Level of Professional Conducts from Health Sciences Students Perspective
}

\author{
Wan Nur Amirah Ibrahim¹, Muhammad Hazwan Husni', Wan Elhami Wan Omar ${ }^{1,2}$ \\ ${ }^{1}$ Centre of Optometry Studies, Faculty of Health Sciences, Universiti Teknologi MARA, Cawangan Selangor, Kampus Puncak Alam, \\ 42300 Selangor, Malaysia \\ 2 Division of Pharmacy \& Optometry, School of Health Sciences, Faculty of Biology, Medicine \& Health, The University of Manchester, \\ Carys Bannister Building, Dover Street, M13 9PL, Manchester
}

wannuramirah@uitm.edu.my, hazone510@gmail.com,wanelhami.wanomar@postgrad.manchester.ac.uk Tel: +60332584437

\begin{abstract}
Professionalism among health care practitioners is a critical value. This study aimed to determine the acceptable level of professional conduct from the perspective of undergraduate Health Sciences students of UiTM Puncak Alam and compare the difference of perspectives between the years of study. From 320 participants, the results showed the low level of acceptance towards poor scenarios and significant differences in perspectives between the year of study in scenarios 2,3 and 6 ; forging experimental results $\left(X^{2}=18.66, p<0.01\right)$; intellectual dishonesty $\left(X^{2}=11.11, p=0.01\right)$ and forging classmate's signature $\left(X^{2}=11.18, p=0.01\right)$. The findings provided faculty's administrators with an acceptable level of professional conduct from the perspective of their students.
\end{abstract}

Keywords: Professionalism, professional conduct, perspective, Health Sciences students

eISSN: 2398-4287@ 2021. The Authors. Published for AMER ABRA cE-Bs by e-International Publishing House, Ltd., UK. This is an open access article under the CC BYNCND license (http://creativecommons. org/licenses/by-nc-nd/4.0/). Peer-review under responsibility of AMER (Association of Malaysian Environment-Behaviour Researchers), ABRA (Association of Behavioural Researchers on Asians/Africans/Arabians) and cE-Bs (Centre for Environment-Behaviour Studies), Faculty of Architecture, Planning \& Surveying, Universiti Teknologi MARA, Malaysia. DOI: https://doi.org/10.21834/ebpj.v6i18.3077

\subsection{Introduction}

Acknowledging a profession's definition is a must before understanding professionalism. Professionalism is a vital key to being a health care professional (Davis, 2009). Thus, the aspect of professionalism has to be implemented for future professionals as early as their undergraduate study at the university (Hickson et al., 2007). Considering this evidence, health care practitioners are among the highly critical professions in the community (Bruhn, 2001). The study also informed that professionalism applies to all health professionals, whether individuals or collectively involved with patient care (Bruhn, 2001).

However, professional conduct has been a challenging factor to be practised consistently in every situation. It may involve dilemmas in the clinical settings, such as the confidentiality of patient personal information (Olabarrieta-landa et al., 2017). Previous studies reported a high prevalence of healthcare students involved in poor professional misconduct due to unprofessional behaviour during their studies and training in university (Dyrbye et al., 2010; Papadakis et al., 2004; Stern \& Papadakis, 2006). Furthermore, the student involved with negative or unethical behaviour during undergraduate programmes was related to the likelihood of subsequent negative behaviour in their career (Papadakis et al., 2004). As a result, we will face a crisis in healthcare settings where many unprofessional practitioners treat the patients (Glass, 2006).

eISSN: 2398-4287@ 2021. The Authors. Published for AMER ABRA CE-Bs by e-International Publishing House, Ltd., UK. This is an open access article under the CC BYNCND license (http://creativecommons.org/licenses/by-nc-nd/4.0/). Peer-review under responsibility of AMER (Association of Malaysian Environment-Behaviour Researchers), ABRA (Association of Behavioural Researchers on Asians/Africans/Arabians) and CE-Bs (Centre for Environment-Behaviour Studies), Faculty of Architecture, Planning \& Surveying, Universiti Teknologi MARA, Malaysia.

DOI: https://doi.org/10.21834/ebpj.v6i18.3077 
It was important to investigate the students' views on professional behaviour, indicating and predicting their future careers (Marques \& Macedo, 2016). Therefore, this study set out to determine the perspective towards the acceptable level of professional conduct from undergraduate Health Sciences students. The specific objectives of this study are to determine the acceptable level of professional conduct from the perspective of undergraduate Health Sciences students in UiTM Puncak Alam and to compare the perceptions of acceptable professional conduct in different year of study among undergraduate Health Sciences students in UiTM Selangor, Puncak Alam campus. Due to the nature of their future profession, it is expected that Health Sciences students will show low tolerance against poor professional conduct.

\subsection{Literature Review}

\subsection{Attributes of professionalism}

Brehm et al. (2006) believed that students in university need to develop and acquire a wide variety of traits, attitudes, and habits to maintain their professionalism throughout their life persistently. Papadakis et al. (2004) clarified that professionalism is characterised by the medical professionals who display sensitivity to the patients' perspective and put the need of the patients before their desires and needs.

\subsection{Professional misconduct among professionals}

Professional misconduct can be defined as any conduct or behaviours, legal or illegal, that violate normative perspective, expectations, and professional codes of conduct (Muzio et al., 2016). In general, the Malaysian Medical Council defined professional misconduct as a failure to meet the minimum standards of professional medical practice as set out in the Code of Professional Conduct, guidelines, and directives issued by the Council code (Malaysian Medical Council, 2019). However, apart from the health care professionals, the ethical problem also exists among the non-sciences related courses such as engineering, business, and accounting (Forinash et al., 2010; Ismail, 2017).

Brown (2000) stated that professional misconduct is becoming a worrisome problem among health care professionals since there is an increasing number related to the attacks upon children by nurses. In another research, among ten health care professions regulated by law, $31 \%$ of them suspected a colleague was demonstrating professional misconduct (Weenink et al., 2015). Moreover, research among nursing staff in-home care by Maurits et al. (2016) showed a significant number of professional misconducts in which $42 \%$ of the nursing staff was involved in unethical behaviour. Professional misconduct negatively affects the health care system, which is associated with poor patient outcomes, increased malpractice litigation, and decreased patient incitement to continue with follow-up or subsequent health care (Reed et al., 2008).

\subsection{Professional misconduct from university students' perspective}

As Marques \& Macedo (2016) reported, healthcare practitioners were expected to show a high level of ethical principles and professionalism to serve their patients at their best. A previous study showed that most 345 undergraduate nursing students from five different nursing schools in South Korea perceived the action of recording false vital signs as serious misconduct (Park et al., 2014). In the same vein, another study revealed a good general perception towards professional values from the medical students of Universiti Sains Islam Malaysia (USIM). They had achieved the desirable attributes of professionalism of a good Muslim medical doctor (Mohd Rani et al., 2017). In a later study, nursing students scored a high mean score in the Nursing Professional Values Scale-Revised (NPVS-R) questionnaire, which indicates they appreciate the professionalism value as an important value in the nursing profession (Poorchangizi et al., 2019).

Conversely, Ahmad et al. (2008), who investigated the attitudes to ethics issues among Malaysian business students in Multimedia University, showed a contrasting result. The majority of the participants accepted the action of professional misconduct; signing for the absent friend was perceived as a mildly acceptable action in the university (Ahmad et al., 2008). Nevertheless, the prevalence of professional misconduct among students is alarming as they are the health care practitioners-to-be (Papadakis et al., 2004; Stern \& Papadakis, 2006).

In comparing the different years of study, the previous research by Poorchangizi et al. (2019) compared undergraduate students from fourth, sixth, and eighth-semester students. They found no significant difference between the different years of study (Poorchangizi et al., 2019). However, Mohd Rani et al. (2017) showed significant differences in perception towards professional values between the year of study. Both perceptions of professional values between year 4 and year 6 and between year 5 and 6 showed significant differences, with the senior year students having a more positive perception of the professional values (Mohd Rani et al., 2017).

However, the number of published studies on professional conduct among undergraduate students in the university is limited (Trede et al., 2012). Furthermore, no published data has been found on the survey of the perspective of professional misconduct among Health Sciences students in UiTM. Thus, there is much less information known about their perceptions. Hence, it is crucial to implement this study to determine the perspective towards the acceptable level of professional conduct from undergraduate Health Sciences students and compare the perspectives towards the acceptable level of professional conduct between the year of study.

\subsection{Methodology}

The research design used for this study was a cross-sectional study design. The questionnaire was distributed using the Google form platform between February and March 2020. The participants of this study were recruited by using purposive sampling. The full-time undergraduate Health Sciences students of UiTM Puncak Alam were included in this study, while part-time undergraduate and postgraduate students were excluded. 
The Raosoft software was used to calculate the sample size with a $95 \%$ Confidence level, $5 \%$ error, $50 \%$ response distribution, and population size of 1740 . In addition, the $5 \%$ dropout rate of the respondents was considered, making the total number of participants recruited in this study was 328 students. The participants comprised of students from all eight different programmes in the Faculty of Health Sciences. The confidentiality and anonymity of participants were assured. The online-based questionnaire developed by Marques \& Macedo (2016) was adopted in this study. This online-based questionnaire was chosen as the questions applicable to all health sciences students. The questionnaire consisted of seven scenarios of professional conduct. These scenarios were based on the incidents of conduct in the New England College of Optometry (Marques \& Macedo, 2016). The respondents were required to choose between two responses, either "acceptable" or "unacceptable." Six scenarios are poor professional conduct (scenario 1 to 6), while one scenario is good professional conduct (scenario 7). The list of scenarios is presented in Table 1.

Table 1. Scenarios of professional conducts

\begin{tabular}{ll}
\hline Scenario & Description \\
\hline 1. & You find equipment such as a USB pen drive in a \\
hallway. There is no one in sight and do not know to \\
whom it belongs. Finders keepers, you can have the \\
equipment. \\
After lab work, you realize that you forgot to register the \\
experimental results. You are pretty sure that the \\
experimental results were the same as the theoretical, \\
so you record them in the report as such. \\
In the lab, there are several office materials available \\
that you can take without control (e.g. pencil). You are \\
in need of one of these and decide to help yourself. \\
You are really angry at your counsellor. You send him \\
an email to let off steam with knowledge to the entire \\
faculty. \\
You need a reference for an article you are writing. To \\
save money on the photocopy, you cut those pages of \\
the journal. After all, the library typically has multiple \\
copies. \\
You are attending a mandatory class. You know your \\
classmates will come but aren't here yet, so you sign \\
them in the attendance sheet. \\
Your friend confides that he is about to commit suicide. \\
You break confidentiality and tell an administrator.
\end{tabular}

The data of this study were analysed using computer software SPSS version 21. Descriptive statistics have been used to present the demographic characteristics of the students, such as age, gender, programme, and current year of study. The data collected was summarised by calculating the percentage of students giving different answers to each question. Except for the last question, all "acceptable" answers were classified as acceptable towards poor professional conduct. The participants were grouped into four groups based on their respective current year of study. A particular year of study was considered to have a high level of acceptance on the specific scenario of professional conduct if at least $50 \%$ of them accept the particular scenario; low level of acceptance if they scored below $50 \%$. The differences between groups were analysed using Chi-Square tests with $p<0.05$ was considered as statistically significant. This study was approved by the UiTM Research Ethics Committee (REC 2 / 2019, Rev. 1).

\subsection{Findings}

A total of 320 students completed the questionnaire by giving a response rate of $97.6 \%$. Table 2 shows the descriptive statistical results (frequencies and percentages) of participants' demographic data. Most of the participants were female students (76.3\%) and the age range of 21 to 23 years old $(62.8 \%)$. Participants consisted of eight different programmes in the Faculty of Health Sciences. Forty participants from each programme, with ten of them, were from every four batches.

Table 2. Demographic data of UiTM Health Sciences students

\begin{tabular}{lll}
\hline Variables & & $\mathrm{N}(\%)$ \\
\hline Gender & & \\
& Male & $76(23.8)$ \\
\multirow{4}{*}{ Age } & Female & $244(76.3)$ \\
& & \\
& $<21$ years old & $60(18.8)$ \\
& $21-23$ years old & $201(62.8)$ \\
Programme & $>23$ years old & $59(18.4)$ \\
& Dietetics & \\
& Environmental Health and Safety & $40(12.5)$ \\
& Medical Imaging & $40(12.5)$ \\
& Medical Lab Technology & $40(12.5)$ \\
& Nursing & $40(12.5)$
\end{tabular}




\begin{tabular}{cc} 
Occupational Therapy & $40(12.5)$ \\
Optometry & $40(12.5)$ \\
Physiotherapy & $40(12.5)$ \\
Year of Study & \\
First-year & $80(25.0)$ \\
Second-year & $80(25.0)$ \\
Third-year & $80(25.0)$ \\
Fourth-year & $80(25.0)$ \\
\hline
\end{tabular}

A descriptive analysis test was performed to determine the students' perceptions of acceptable professional conduct based on the survey scenarios. Table 3 summarised the responses from 320 participants of their perspectives towards the scenarios of professional conduct. Overall, all participants showed a low level of acceptance $(<50 \%)$ towards the seven professional conducts except for scenarios 2 and 7 . In scenario 2, only first-year students had a high level of acceptance for poor professional conduct. While in scenario 7 , all four years of the study showed a high level of acceptance for good professional conduct.

Table 3 also showed the statistical analysis by frequencies, percentages, and Chi-Square tests to compare the acceptance of misconducts between the year of study. Based on Table 3, three scenarios showed a significant difference between the year of study $(p<0.05)$. The three scenarios are scenario 2: forging experimental result, scenario 3: intellectual dishonesty, and scenario 6 : forging classmate's signature, while other scenarios had no significant difference $(p>0.05)$.

\begin{tabular}{|c|c|c|c|c|c|c|c|}
\hline Scenario & Answer & First-year & Second-year & Third-year & Fourth-year & $\begin{array}{l}x^{2} \\
(n=320, d f=7)\end{array}$ & $p$-value \\
\hline 1 & $\begin{array}{l}\text { Acceptable } \\
\text { Unacceptable }\end{array}$ & $\begin{array}{l}5(6.3 \%) \\
75(93.8 \%)\end{array}$ & $\begin{array}{l}0(0 \%) \\
80(100 \%)\end{array}$ & $\begin{array}{l}1(1.3 \%) \\
79(98.8 \%)\end{array}$ & $\begin{array}{l}4(5.0 \%) \\
76(95.0 \%)\end{array}$ & 7.02 & 0.07 \\
\hline 2 & $\begin{array}{l}\text { Acceptable } \\
\text { Unacceptable }\end{array}$ & $\begin{array}{l}44(55.0 \%) \\
36(45.0 \%)\end{array}$ & $\begin{array}{l}20(25.0 \%) \\
60(75.0 \%)\end{array}$ & $\begin{array}{l}23(28.8 \%) \\
57(71.3 \%)\end{array}$ & $\begin{array}{l}32(40.0 \%) \\
48(60.0 \%)\end{array}$ & 18.66 & $<0.01$ \\
\hline 3 & $\begin{array}{l}\text { Acceptable } \\
\text { Unacceptable }\end{array}$ & $\begin{array}{l}14(17.5 \%) \\
66(82.5 \%)\end{array}$ & $\begin{array}{l}2(2.5 \%) \\
78(97.5 \%)\end{array}$ & $\begin{array}{l}6(7.5 \%) \\
74(92.5 \%)\end{array}$ & $\begin{array}{l}10(12.5 \%) \\
70(87.5 \%)\end{array}$ & 11.11 & 0.01 \\
\hline 4 & $\begin{array}{l}\text { Acceptable } \\
\text { Unacceptable }\end{array}$ & $\begin{array}{l}3(3.8 \%) \\
38(96.3 \%)\end{array}$ & $\begin{array}{l}1(1.3 \%) \\
79(98.8 \%)\end{array}$ & $\begin{array}{l}2(2.5 \%) \\
78(97.5 \%)\end{array}$ & $\begin{array}{l}3(3.8 \%) \\
38(96.3 \%)\end{array}$ & 1.26 & 0.88 \\
\hline 5 & $\begin{array}{l}\text { Acceptable } \\
\text { Unacceptable }\end{array}$ & $\begin{array}{l}2(2.5 \%) \\
78(97.5 \%)\end{array}$ & $\begin{array}{l}5(6.3 \%) \\
75(93.8 \%)\end{array}$ & $\begin{array}{l}6(7.5 \%) \\
74(92.5 \%)\end{array}$ & $\begin{array}{l}6(7.5 \%) \\
74(92.5 \%)\end{array}$ & 2.41 & 0.52 \\
\hline 6 & $\begin{array}{l}\text { Acceptable } \\
\text { Unacceptable }\end{array}$ & $\begin{array}{l}13(16.3 \%) \\
67(83.8 \%)\end{array}$ & $\begin{array}{l}16(20.0 \%) \\
64(80.0 \%)\end{array}$ & $\begin{array}{l}10(12.5 \%) \\
70(87.5 \%)\end{array}$ & $\begin{array}{l}26(32.5 \%) \\
54(67.5 \%)\end{array}$ & 11.18 & 0.01 \\
\hline 7 & $\begin{array}{l}\text { Acceptable } \\
\text { Unacceptable }\end{array}$ & $\begin{array}{l}55(68.8 \%) \\
25(31.3 \%) \\
\end{array}$ & $\begin{array}{l}54(67.5 \%) \\
26(32.5 \%) \\
\end{array}$ & $\begin{array}{l}56(70.0 \%) \\
24(30.0 \%) \\
\end{array}$ & $\begin{array}{l}59(73.8 \%) \\
21(26.3 \%) \\
\end{array}$ & 0.83 & 0.87 \\
\hline
\end{tabular}

Scenario 2 had significant differences for perspectives towards the level of acceptable professional conduct between the year of study $\left(x^{2}=18.66, p<0.01\right)$. Figure 1 showed the percentages of responses by four years of study on scenario 2 , with the most acceptable answer from first-year students (37.0\%). Most freshmen accepted poor professional conduct as acceptable conduct (55.0\%).

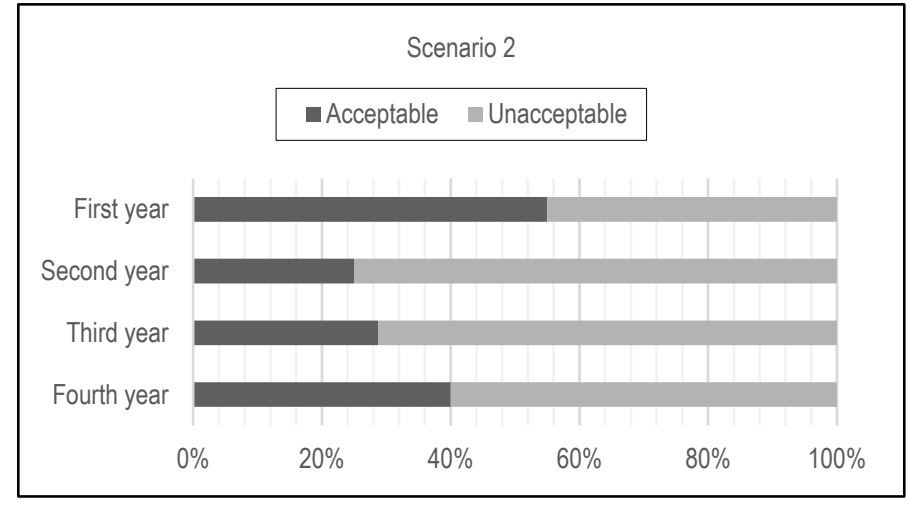

Fig. 1: Perspective on scenario 2 from four groups year of study among Health Sciences students

Scenario 3 had significant differences for perspectives towards the level of acceptable professional conduct between the year of study $\left(x^{2}=11.11, p=0.01\right)$. Figure 2 showed the percentages of responses by four years of study on scenario 3 , with the most acceptable answer being from first-year students (43.8\%). 


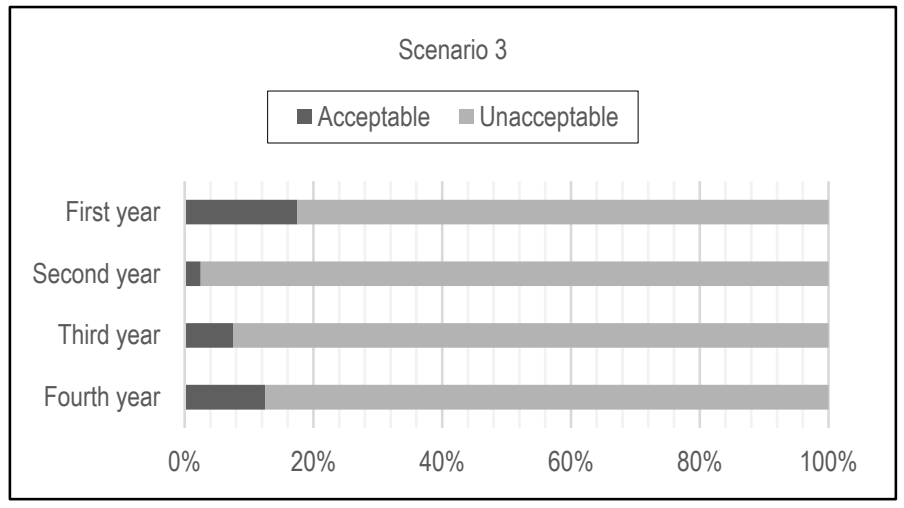

Fig. 2: Perspective on scenario 3 from four groups year of study among Health Sciences students

Scenario 6 had significant differences for perspectives towards the level of acceptable professional conduct between the year of study $\left(x^{2}=11.18, p=0.01\right)$. Figure 3 showed the percentages of responses by four years of study on scenario 6 , with the most acceptable answer, from fourth-year students $(32.5 \%)$.

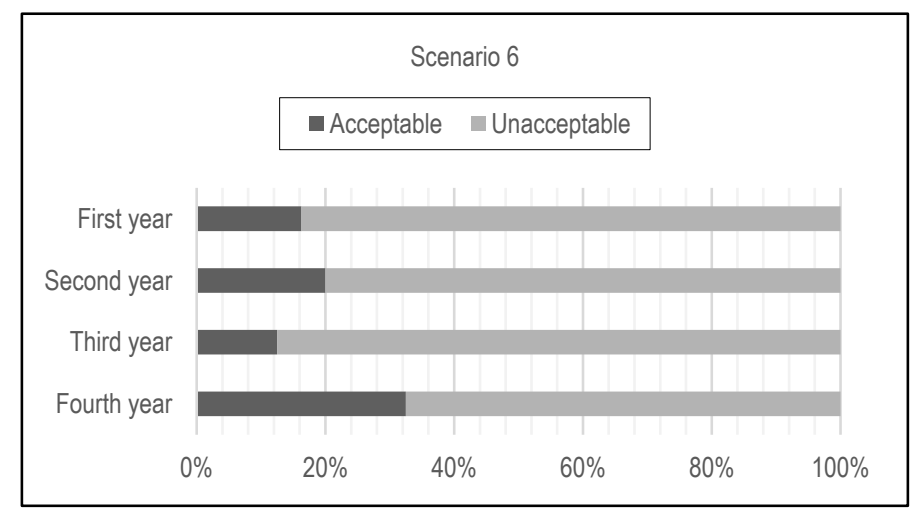

Fig. 3: Perspective on scenario 6 from four groups year of study among Health Sciences students

\subsection{Discussion}

In the first objective, the results followed the trend corresponding to the initial prediction. Generally, all the participants showed low acceptance $(<50 \%)$ towards the poor professional conduct in the six scenarios except for scenario 2 , forging experimental results. In the scenario, the first-year student group was the only group that showed a high level of acceptance $(\geq 50 \%)$ towards poor professional conduct.

A low level of acceptance towards poor professional conduct or professional misconduct among Health Sciences students in this study proved high professional values among them. Similarly, a study by Poorchangizi et al. (2019) also resulted in a high mean total of professional values from the nursing student's perspective, which indicated a high level of consciousness and awareness of the importance of professional values among the students. The study showed that the participants had a low level of acceptance towards professional misconduct (Poorchangizi et al., 2019). A study by Mohd Rani et al. (2017) also had a similar result whereby the medical students of Universiti Sains Islam Malaysia (USIM) had an overall low level of acceptance toward poor professional conduct with good perception towards the professional values.

Next, the finding showed significant differences between the year of study in three scenarios; scenario 2; forging experimental result, scenario 3; intellectual dishonesty and lastly, scenario 6; forging signatures. Both first two scenarios (scenarios 2 and 3) had higher tolerance from first-year students' perspective, while in scenario 6, the highest acceptable answer was from the fourth-year students. In the same vein, a previous study by Mohd Rani et al. (2017) also showed a significant difference between students' different years of study towards their professional values.

In scenario 2, there was a significant difference between the year of study, with most of the acceptable answers from the first-year students (37.0\%). Most of the first-year students (55.0\%) accepted poor professional conduct in scenario 2.

This high level of acceptance towards poor professional conduct from the freshman was contrary to the study by Park et al. (2014). In the study, $43.1 \%$ of students categorised the action of recording false vital signs as serious unethical clinical behaviour, while only $33.2 \%$ and $13.8 \%$ of students categorised it as moderate and trivial action, respectively (Park et al., 2014). This situation of forging experimental results is one of the professional abuse in health care professionals practice (Malaysian Medical Council, 2019). As stated by the Malaysian Medical Council (2019), in the "Code of Professional Conduct 2019," a practitioner must avoid erasing, obliterating, tampering, or altering the clinical records. In their study, Park et al. (2014) had explained the possible reasons for recording inaccurate 
vital signs by nursing students. The potential reasons were that the students might forget the vital signs that need to be recorded and lack of time to reassure the data due to the packed schedule as a nursing student. Most of the freshman reporting inaccurate experiment data might be due to avoiding any unfavourable data deviated from the theory concept (Park et al., 2014). So, the students opted for a normal range of result records in their lab reports instead of abnormal data (Park et al., 2014).

Our findings in scenario 3 (intellectual dishonesty) showed a significant difference between groups, and first-year students contributed to the highest number of acceptable answers (43.8\%). The first-year students who accepted the intellectual dishonesty situation are probably due to the inexpensive office materials (Park et al., 2014). In addition, seeing the other staff or senior students doing the same action was another factor for the freshman to consider scenario 3 as an acceptable behaviour (Park et al., 2014). Moreover, Mohd Rani et al. (2017) proved that junior students had lower awareness of professional values. This was because the junior students attended less professionalism-related courses than their seniors (Mohd Rani et al., 2017). In addition, it may reveal that maturity among senior students who seem to be more responsible and precise in their tasks (Marques \& Macedo 2016).

The third scenario, scenario 6; forging a classmate's signature, showed a significant difference among the year of study. The fourthyear students had the most acceptable answer in the scenario (32.5\%). The result was the same as the study by Ahmad et al. (2008), where the student's attitudes towards signing for absent friends were mildly acceptable. The students' tolerance could be due to the low possibility of getting caught by the action, and the students may think that the signing for friends was assumed as a "friendly help" and not an unethical issue (Ahmad et al., 2008).

On the whole, this study's result indicated an excellent professional conduct perspective from the Health Sciences students. However, understanding and valuing the importance of professionalism by involving students in professional activities such as registering in ethics course, students symposium and conference may contribute to the development of professionalism among students (Mohd Rani et al., 2017; Poorchangizi et al., 2019). In addition, health sciences students should require basic educational principles, technical skills and understand the objectives and outcome of their course to improve and strengthen their professionalism. Therefore, the students are expected to apply professional behaviour in their future practices. As future health care practitioners, the Health Sciences students are supposedly capable of implementing good professional conduct and values in making decisions whenever they face related ethical situations in the health care area (Poorchangizi et al., 2019). Moreover, study on the acceptable level of professional conduct among health sciences students who are the primary care and have direct contact with patients is useful and relevant as the results could provide feedback on the effectiveness of the health care professional.

\subsection{Conclusion \& Recommendations}

This study showed that the participants have a low level of acceptance towards poor professional conduct. The study also found that there was a significant difference between the year of study in three scenarios of professional conduct. This gave the Faculty of Health Sciences administrator insight into the level of acceptable professional conduct from their students' perspectives. Hence, they can plan to improve and enhance the current curricular in teaching professionalism value to the students. Teaching professionalism in the university to undergraduate Health Sciences students can minimise the occurrence of unprofessional behaviour in their workplace in the future.

There was some limitation to this analysis that should be addressed and acknowledged in future studies. The study sample for this study was only limited to one university; thus, the generalisation of the findings was limited. Therefore, participants from other universities in Malaysia are recommended in future studies, and it will able the generalisation of the findings of university students in Malaysia. In addition, more comprehensive demographic data should be collected by future researchers, such as social, family background, and the method of teaching professionalism.

As the first research of professional values among Health Sciences students in UiTM Puncak Alam, this study had set a baseline for the next related research. Further research on lecturers' and students' capability of implementing the professionalism value during the learning session is recommended to be consistent, reflective practitioners and the need to use developing technologies to promote high-quality student learning.

\section{Acknowledgements}

The authors would like to thank the Health Sciences students in Universiti Teknologi MARA Cawangan Selangor (UCS), Puncak Alam Campus, for contributing to this study. This project is self-funded.

\section{Paper Contribution to Related Field of Study}

This paper contributes to the field of healthcare and quality of life.

\section{References}

Ahmad, Z., Simun, M., \& Mohammad, J. (2008). Malaysian university students' attitudes to academic dishonesty and business ethics. Asia Pacific Journal of Education, 28(2), $149-160$.

Brehm, B., Breen, P., Brown, B., Long, L., Smith, R., Wall, A., \& Warren, N. S. (2006). An interdisciplinary approach to introducing professionalism. American Journal of Pharmaceutical Education, 70(4). 
Brown, A. D. (2000). Making Sense of Inquiry Sensemaking. Journal of Management Studies, 37(1). https://doi.org/10.1111/1467-6486.00172

Bruhn, J. G. (2001). Being good and doing good: the culture of professionalism in the health professions. The Health Care Manager, 19(4), 47-58.

Davis, D. S. (2009). Teaching professionalism: A Survey of Physical Therapy Educators. Journal of Allied Health, 38(2), 74-80.

Dyrbye, L. N., Massie, F. S., Eacker, A., Harper, W., Power, D., Durning, S. J., Thomas, M. R., Moutier, C., Satele, D., Sloan, J., \& Shanafelt, T. D. (2010). Relationship between burnout and professional conduct and attitudes among US medical students. JAMA - Journal of the American Medical Association, 304(11), 1173-1180. https://doi.org/10.1001/jama.2010.1318

Forinash, A. B., Smith, W. T., Gaebelein, C. J., \& Garavaglia, J. (2010). Differences in self-reported academically dishonest and nondishonest pharmacy students when rating professional dishonesty scenarios. Currents in Pharmacy Teaching and Learning, 2(2), 100-107. https://doi.org/10.1016/j.cptl.2010.01.004

Glass, A. R. (2006). Unprofessional behavior among medical students. The New England journal of medicine, 354(17), 1851.

Hickson, G. B., Pichert, J. W., Webb, L. E., \& Gabbe, S. G. (2007). A complementary approach to promoting professionalism: identifying, measuring, and addressing unprofessional behaviors. Academic Medicine, 82(11), 1040-1048.

Ismail, S. (2017). Ethical judgment and ethical ideology of accounting professionals and accounting students. Asian Journal of Accounting Perspectives, 10(1), 99-113.

Malaysian Medical Council. (2019). Code of Professional Conduct 2019. (2019). Retrieved from https://mmc.gov.my/wp-content/uploads/2019/12/CODE-OFPROFESSIONAL-CONDUCT-2019-Amended-Version.pdf

Marques, D. N., \& Macedo, A. F. (2016). Perceptions of acceptable conducts by university students. Journal of Optometry, 9(3), 166-174. https://doi.org/10.1016/j.optom.2015.02.001

Maurits, E. E., de Veer, A. J., Groenewegen, P. P., \& Francke, A. L. (2016). Dealing with professional misconduct by colleagues in home care: a nationwide survey among nursing staff. BMC nursing, 15(1), 59

Mohd Rani, M. D., Jamaludin, J., Azmi, A. N., Ramli, S., Subri, M. I., Osman, A., \& Nik Ismail, N. M. N. (2017). Perception of Medical Professionalism among Clinical Students at Universiti Sains Islam Malaysia. Journal of Medicine, 18(2), 56-61. https://doi.org/10.3329/jom.v18i2.33678

Muzio D, Faulconbridge J, Gabbioneta C and Greenwood R (2016) Bad Apples, Bad Barrels and Bad Cellars: A 'Boundaries' Perspective on Professional Misconduct. In Palmer D, Greenwood R and SmithCrowe K (eds) Organizational Wrongdoing. Cambridge, UK: Cambridge University Press: 141-175.

Olabarrieta-landa, L., Caracuel, A., \& Panyavin, I. (2017). Perception of ethical misconduct by neuropsychology professionals in Spain. 41, 527-538. https://doi.org/10.3233/NRE-162144

Papadakis, M. A., Hodgson, C. S., Teherani, A., \& Kohatsu, N. D. (2004). Unprofessional behavior in medical school is associated with subsequent disciplinary action by a state medical board. Academic Medicine, 79(3), 244-249.

Park, E. J., Park, S., \& Jang, I. S. (2014). Clinical misconduct among South Korean nursing students. Nurse Education Today, 34(12), 1467-1473. https://doi.org/10.1016/j.nedt.2014.04.006

Poorchangizi, B., Borhani, F., Abbaszadeh, A., Mirzaee, M., \& Farokhzadian, J. (2019). The importance of professional values from nursing students' perspective. BMC nursing, 18(1), 26.

Reed, D. A., West, C. P., Mueller, P. S., Ficalora, R. D., Engstler, G. J., \& Beckman, T. J. (2008). Behaviors of highly professional resident physicians. JAMA - Journal of the American Medical Association, 300(11), 1326-1333. https://doi.org/10.1001/jama.300.11.1326

Stern, D. T., \& Papadakis, M. (2006). The developing physician-becoming a professional. New England Journal of Medicine, 355(17), 1794-1799.

Trede, F., Macklin, R., \& Bridges, D. (2012). Professional identity development: a review of the higher education literature. Studies in Higher Education, 37(3), 365-384.

Weenink, J. W., Westert, G. P., Schoonhoven, L., Wollersheim, H., \& Kool, R. B. (2015). Am I my brother's keeper? A survey of 10 healthcare professions in the Netherlands about experiences with impaired and incompetent colleagues. BMJ Quality \& Safety, 24(1), 56-64. https://doi.org/10.1136/bmjqs-2014-003068 